\title{
Soldering of steel sheets and zinc-coated aluminum by hybrid composite forging
}

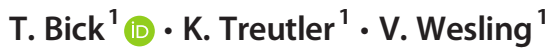

Received: 16 January 2019 / Accepted: 14 October 2020 / Published online: 26 October 2020

(C) The Author(s) 2020

\begin{abstract}
In lightweight construction, light metals like aluminum are used in addition to high-strength steels. However, a welded joint of aluminum and steel leads to the precipitation of brittle, intermetallic phases and contact corrosion. Nevertheless, to use the advantages of this combination in terms of weight saving, composite hybrid forging has been developed. In this process, an aluminum solid part and a steel sheet were formed in a single step and joined at the same time with zinc as brazing material. For this purpose, the zinc was applied by hot dipping on the aluminum in order to produce a Brazing via these layers in a forming process, under pressure and heat. Due to the formed intermediate layer of zinc, the formation of the Fe-Al intermetallic phases and the contact corrosion are excluded. By determining the mathematical relationships between joining parameters and the mechanical properties of the joint, the strength of a specific joint geometry could be adjusted to reach the level of conventional joining techniques. In addition to the presentation of the joint properties, the influence of the joining process on the structure of the involved materials will be shown. Furthermore, the failure behavior under static tensile and shear stress will be shown.
\end{abstract}

Keywords Soldering $\cdot$ Aluminum $\cdot$ Steel $\cdot$ Hybrid composite forging

\section{Introduction}

Lightweight construction is increasingly being built in multimaterial construction to save weight and resources. Especially in the car body, in addition to high-strength steels, light metals such as aluminum and magnesium are used. But aluminum and steel can only be joined together to a limited degree,

Recommended for publication by Commission XVII - Brazing, Soldering and Diffusion Bonding

T. Bick

tobias.bick@tu-clausthal.de

K. Treutler

treutler@isaf.tu-clausthal.de

V. Wesling

office@ isaf.tu-clausthal.de

1 Institute of Welding and Machining, Clausthal University of Technology, Agricolastrasse 2, 38678 Clausthal-Zellerfeld, Germany because in molten state, brittle intermetallic phases are formed, which can reach up to $1100 \mathrm{HV}[1,2]$. Meco et al. investigated the influence of the intermetallic phases and the width of the heat-affected zone as a function of the temperature during the laser beam welding of aluminum and steel [3]. They showed that a narrow heat-affected zone with a low proportion of intermetallic phases is as damaging to the strength as large distinct phases themselves [4, 5]. Kashani et al. showed that the strength of laser overlap welded joints increases when the size of the intermetallic phase seam is less than $10 \mu \mathrm{m}$ [6]. Zhang et al. investigated the influence of a zinc layer between aluminum and steel by using friction stir welding [7]. It was found that the zinc from the coating of the steel sheet has a positive influence on the formation of the intermetallic phases and thus on the strength. Dong et al. used a zinc filler material for tungsten inert gas welding of the aluminum alloy 5A02 and the steel Q235. The zinc filler material causes a discontinuous and uneven intermetallic compound layer with a thickness lower than $10 \mu \mathrm{m}$. But the evaporation of zinc results in pores that often formed in the joint [8]. Dharmendra et al. used a laser welding-brazing process 
Fig. 1 Probe geometry of used aluminum solid parts

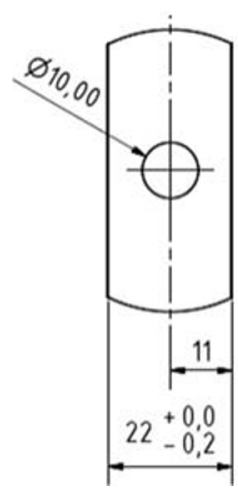

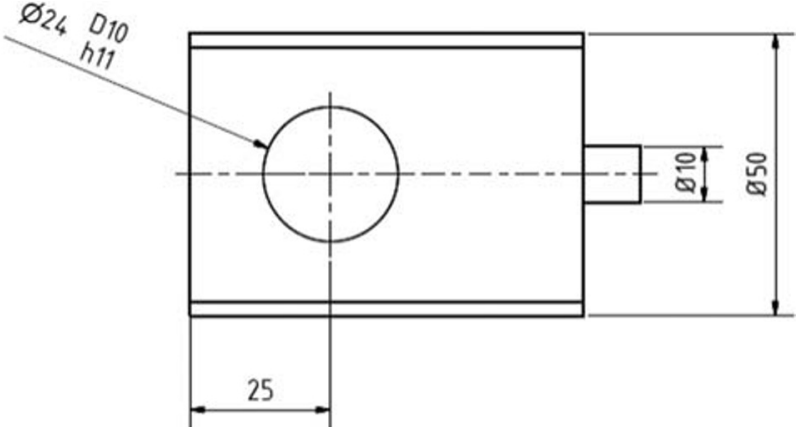

for joining AA6016 and DP600 with a zinc filler wire. The molten zinc wetted the steel surface and melted the surface on the aluminum opposite. Thereby, a small intermetallic compound layer was build. But the molten material results in the hard phases, too [9]. Chen et al. shows that the formation of intermetallic phases in steel aluminum joints is a result of diffusion. They used the resistance spot welding process for joining A5052 and DP 600 [10]. An additional layer of zinc or nickel between the two materials impacts the diffusion and the growth of intermetallic compounds $[11,12]$. However, in no joining process could the formation of the intermediate phases be completely inhibited, because all processes based on a

Table 1 Chemical composition of AlMg4,5Mn and DX54D + Z100

\begin{tabular}{ll}
\hline AlMg4,5Mn & \\
Element & at.- $\%$ \\
$\mathrm{Al}$ & 94.3 \\
$\mathrm{Mg}$ & 4489 \\
$\mathrm{Mn}$ & 0.515 \\
$\mathrm{Fe}$ & 0.3042 \\
$\mathrm{Si}$ & 0.1555 \\
$\mathrm{Cr}$ & 0.0796 \\
$\mathrm{Zn}$ & 0.047 \\
$\mathrm{Cu}$ & 0.0403 \\
$\mathrm{Ni}$ & 0.0020 \\
$\mathrm{DX} 54 \mathrm{D}$ & \\
\hline
\end{tabular}

99.47

$\mathrm{Fe}$

0.011

0.029

$\begin{array}{ll}\mathrm{Mn} & 0.113 \\ \mathrm{P} & 0.012\end{array}$

$\mathrm{S} \quad 0.0082$

Ti

Zinc layer (Z100)

$\mathrm{Zn}$

$\mathrm{Fe}$

Al molten phase for joining steel and aluminum. Also the friction stir welding process for joining in solid state results in a formation of intermetallic compounds by mixing the materials under heat input [13-16].

A new approach is therefore the creation of a material joint by composite forging of aluminum and steel with a zinc interlayer. In the case of composite forging, form-fitting, forcefitting, and/or material-locking connections are produced by hot forming [17-21]. While joining, the materials are not transferred to the molten state during forming under heat. In this research, galvanized steel sheets of DX 54D joined with AlMg4,5Mn solid components. In addition to the zinc coating on the steel side, a second zinc alloy layer on the aluminum base material is used to exclude the directly contact between the two base materials. The low melting temperature of the zinc $\left(T_{\mathrm{S}}=420^{\circ} \mathrm{C}\right)$ is below the melting point of aluminum $\left(T_{\mathrm{S}}=660^{\circ} \mathrm{C}\right)$ and steel $\left(T_{\mathrm{S}}=\mathrm{ca} .1500{ }^{\circ} \mathrm{C}\right)$. This could lead to the formation of a molten phase and finally to a metallic continuity joint without mixing aluminum and steel.

\section{Used materials and geometries}

For the investigation, solid parts shown in Fig. 1 of AlMg4,5Mn were firmly joined to sheet metal of a deepdrawing quality DX54D + Z100. In a first step, the solid parts were coated with a layer of alloyed zinc.

Table 2 Material properties of AlMg4,5Mn and DX54D + Z100

\begin{tabular}{lll}
\hline & AlMg4,5Mn & DX54D + Z100 \\
\hline Ultimate strength & $329 \mathrm{MPa}$ & $260 \mathrm{MPa}$ \\
Yield strength & $223 \mathrm{MPa}$ & $120 \mathrm{MPa}$ \\
Young's modulus & $92.400 \mathrm{MPa}$ & $210.000 \mathrm{MPa}$ \\
Breaking elongation & $14,36 \%$ & $36 \%$ \\
Compression strength & $328 \mathrm{MPa}$ & - \\
\hline
\end{tabular}


Fig. 2 Binary phase diagram of aluminum and zinc [22]

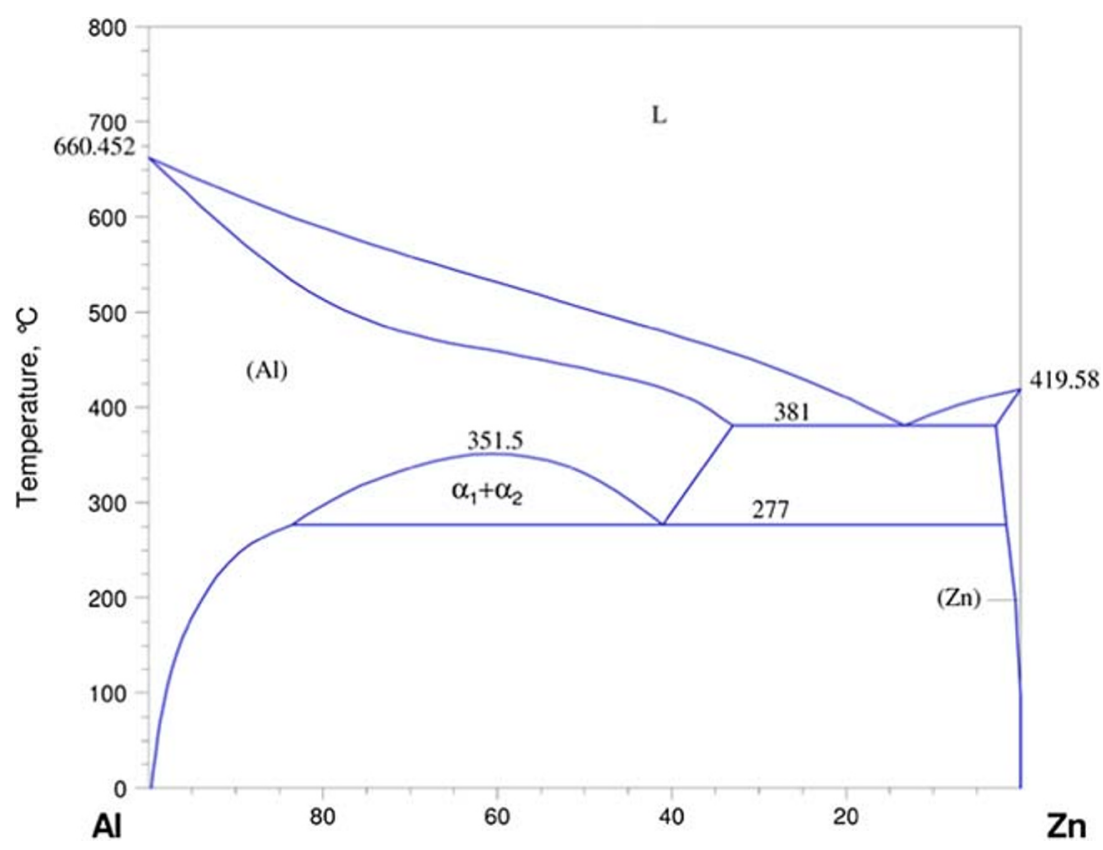

The chemical composition of the aluminum alloy and the steel sheet was determined by spectrometry. The results are listed in Table 1. In addition to that, the composition of the zinc coating on the steel surface was determined by EDX analysis.

The mechanical properties of the materials are shown in Table 2.

The aluminum material has good weldability and corrosion resistance but only a restricted solderability. The most common areas of application include apparatus, container, and vehicle construction. Due to its good low-temperature properties and sea water resistance, this alloy is also used in shipbuilding.

In contrast, the hot-dip galvanized deep-drawing steel DX 54 is predominantly used in vehicle construction.

\section{Hot dipping of aluminum}

The zinc alloy layer on the aluminum solid part is applied by hot dip galvanizing. For this purpose, the process of piece galvanizing steel was transferred. So, the solid parts were stored in a crucible filled with the liquid molten zinc alloy for $20 \mathrm{~min}$ at $420{ }^{\circ} \mathrm{C}$ in the oven. After that, the solid parts were took out of the molten zinc alloy and stored at the atmosphere for cooling. It results in a $150-\mu \mathrm{m}$ zinc layer on the AlMg4,5Mn solid parts. The molten zinc used for coating the aluminum alloy is a near-eutectic zinc-aluminum alloy, with a composition of 83 at.- $\% \mathrm{Zn}$ and 17 at.- $\%$ aluminum. The amount of aluminum in the molten zinc is needed to avoid corrosion effects on the solid part edges due to the lowmelting eutectic, while the coating procedure.

Figure 2 shows the diagram of the binary system Al-Zn. The composition corresponds to 17 at.- $\%$ aluminum and 83 at. $\%$ zinc and thus lies to the left of the eutectic (hypoeutectic alloy). The melting temperature of the alloy was determined to be $381{ }^{\circ} \mathrm{C}$. The layer thickness of the zinc coating produced on the aluminum bolt (Fig. 3) is between 50 and $200 \mu \mathrm{m}$. In the transverse section, a small diffusion layer can be seen below this layer, which arises during the galvanizing process. In addition to that, the coating layer is separated from the substrate. The influence of the coating to the typical oxide layer of aluminum and its alloys is still under research.

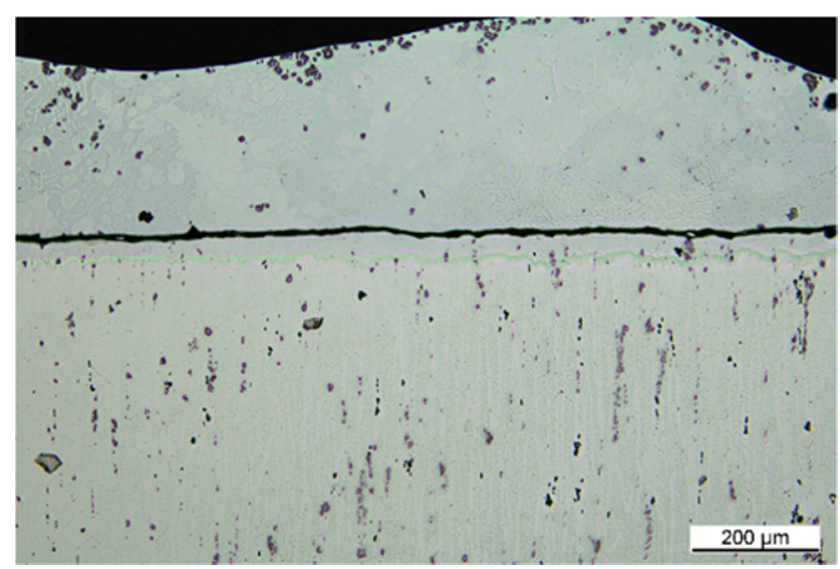

Fig. 3 Coating of zinc alloy on AlMg4,5Mn solid part 
Fig. 4 Test setup

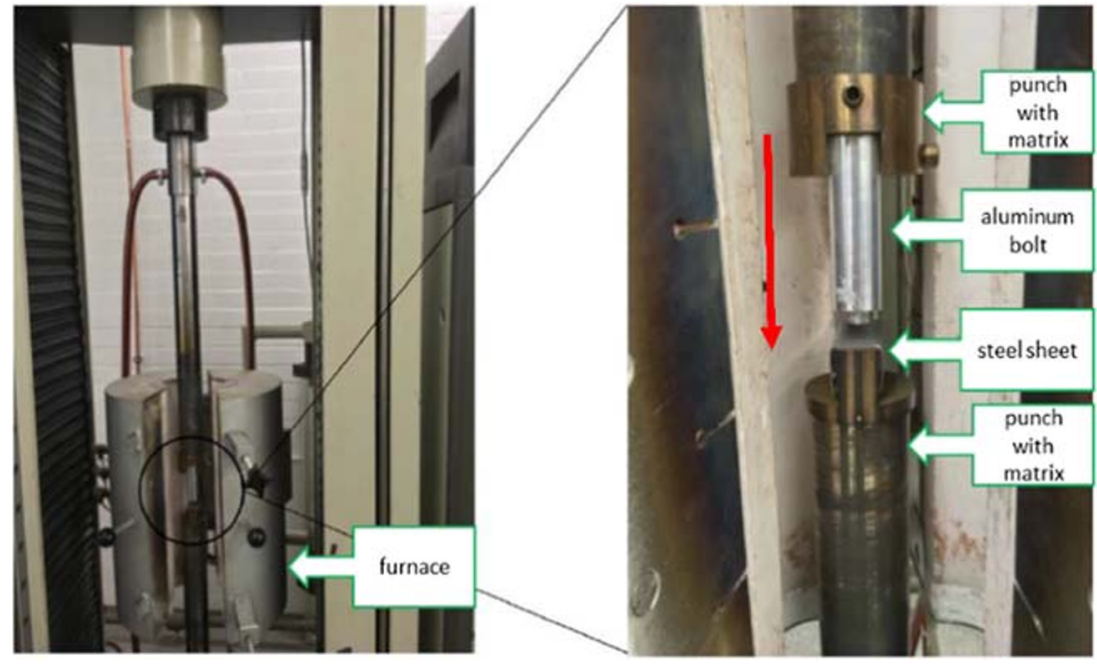

The investigation of the coating in a scanning electron microscope with energy-sparse X-ray spectrometry (EDX) revealed that a nearly pure zinc layer is formed on the surface. The increasing amount of zinc is maybe a result of the reaction between the molten zinc alloy and the AlMg4,5Mn solid part, caused by the concentration gradient of zinc.

\section{Joining of aluminum and steel sheets}

The joining process of compound forging was simulated with a train-compression test rig with integrated furnace. The experimental setup is shown in Fig. 4. The solid parts were clamped on the upper punch and heated by natural convection in the oven for $20 \mathrm{~min}$. Subsequently, the predetermined force is approached at the predetermined punch speed in the direction of the red arrow in the figure. On the lower punch, the produced steel sheet samples were inserted and also preheated. In order to be able to determine a process window for the production of metallic continuity through hybrid composite forging, the process parameters were varied in a Doptimal design. The ranges of the DoE are shown in Table 3.

This allows a reliable statement about the behavior of the entire system with relatively little effort.

In Fig. 5, the courses of temperature for the two punches and the specimens are shown. The used joining parameters are $455{ }^{\circ} \mathrm{C}$ in the oven, $27.5 \mathrm{kN}$ punching force, and a traverse

Table 3 Ranges of joining parameters for DoE

\begin{tabular}{ll}
\hline Furnace temperature & $375-500{ }^{\circ} \mathrm{C}$ \\
Specimen temperature & $220-375{ }^{\circ} \mathrm{C}$ \\
Punch speed & $5-18 \mathrm{~mm} / \mathrm{min}$ \\
Punch force & $15-40 \mathrm{kN}$ \\
\hline
\end{tabular}

speed of $11.5 \mathrm{~mm} / \mathrm{min}$. The temperature courses were measured with thermoelements in the top and bottom clamping devices as well as on the steel sheet surface and $2 \mathrm{~mm}$ over the surface in the AlMg4.5Mn solid part. The maximum temperature of the steel sheet is $320{ }^{\circ} \mathrm{C}$ and at the AlMg4.5Mn part $290{ }^{\circ} \mathrm{C}$. At the point of contact, the temperature of the two parts aligns to a level of $295^{\circ} \mathrm{C}$. Figure 6 shows the courses of force and the traverse way. The little pin at the top of the solid part is continuously formed during the joining process. The final degree of deformation is about $82 \%$.

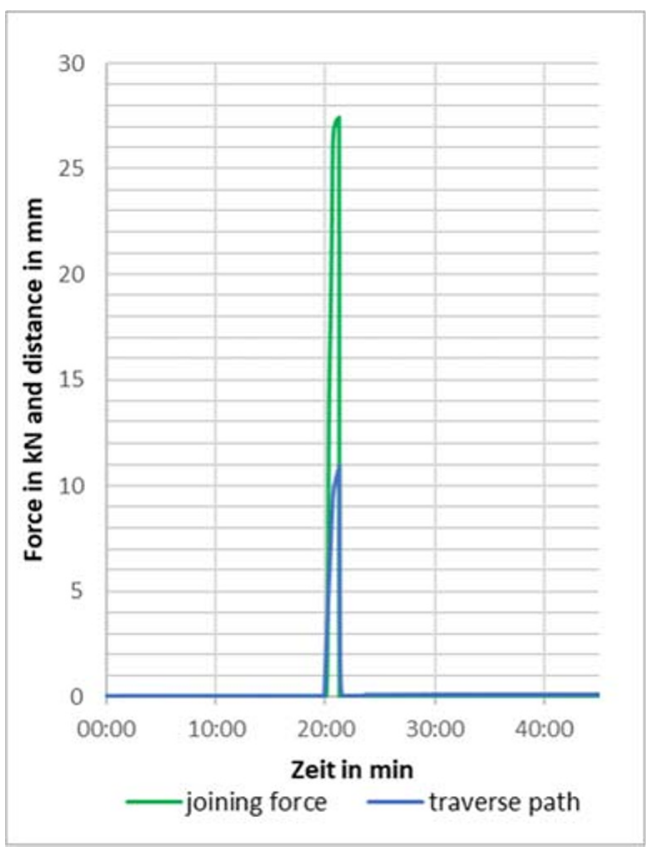

Fig. 5 Temperature courses for the parameters $27.5 \mathrm{kN}, 11.5 \mathrm{~mm} / \mathrm{min}$ and $455^{\circ} \mathrm{C}$ 


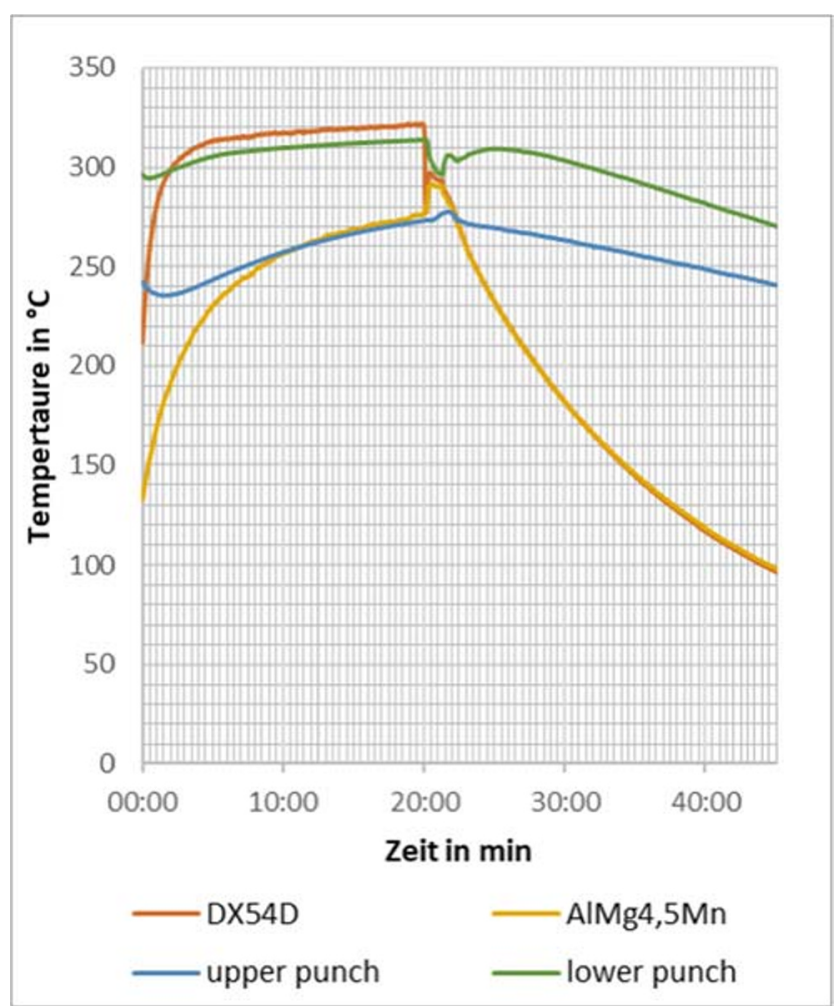

Fig. 6 Course of joining force and traverse path

In Fig. 7, the joint zone is shown. The deformation lines in the microstructure can be seen.

\section{Results}

As the temperature curves have shown, the temperature in the joining zone deviates considerably from the melting temperature of the zinc alloy in the coating zone of the AlMg4.5Mn solid part. The cross section of the joining zone in Fig. 8 shows the soldering zone of the two zinc layers and the base

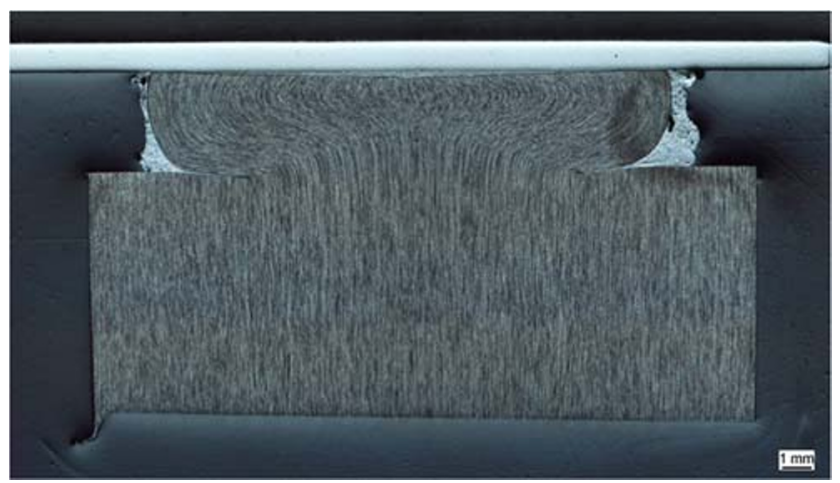

Fig. 7 Metallographic cross section of the joint zone

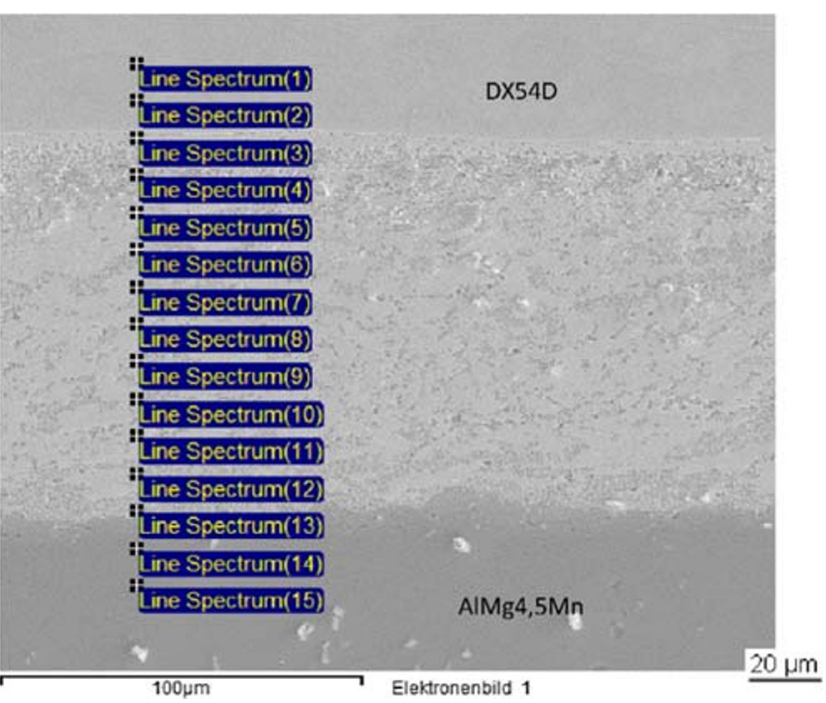

Fig. 8 Joining area with measurement points for EDX analysis

materials. The picture was taken by SEM, and at the 15 points in the picture, EDX analysis was carried out.

From the EDX analysis, a distribution of the chemical elements in the joint zone has been determined quantitatively (Fig. 9). Therefore, three measurement rows were determined with a distance of $50 \mu \mathrm{m}$ and $100 \mu \mathrm{m}$ to the first row.

On the upper side in the picture is the steel base material and on the bottom side the aluminum alloy base material. The iron content therefore decreases abruptly at the boundary to the zinc layer. Along with this decrease, the zinc and the aluminum content increase. The course of the scan for aluminum and zinc suggests that zinc-aluminum mixed crystals have formed in the joint zone. An EDX analysis of the chemical composition of the phases formed in the junction zone has confirmed this assumption. In the transition to the aluminum base material, the quantity of aluminum in the course

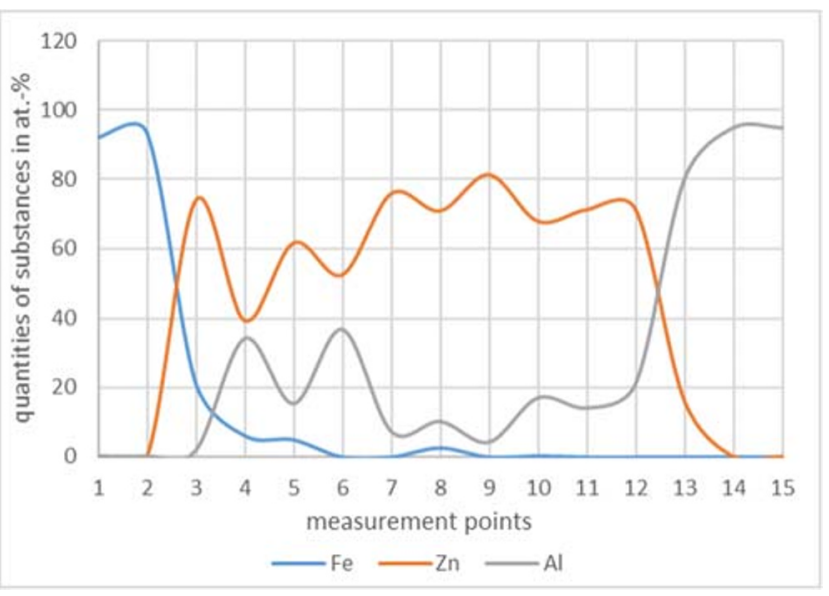

Fig. 9 Concentration gradient of iron, aluminum, and zinc in the joining area 
Table 4 Joining parameters for specimens with maximum strength

\begin{tabular}{llll}
\hline & K13 & K14 & K15 \\
\hline Specimen temperature in ${ }^{\circ} \mathrm{C}$ & 330 & & \\
Force in $\mathrm{kN}$ & 27.5 & \\
Speed in $\mathrm{mm} / \mathrm{min}$ & 11.5 & & \\
\hline
\end{tabular}

increases significantly. Zinc and iron, however, are close to zero. Based on this result, diffusion of the iron into the aluminum base material can be excluded. Only in the joint zone are iron-zinc mixed crystals to be found. The formation of the brittle intermetallic phases was thus largely suppressed. On the other hand, the base material of the DX54 $+\mathrm{Z}$ does not show any diffusion-dependent influence by the aluminum.

The determined quantity of the elements in the joining zone suggests that a cohesive zinc-zinc compound was produced from the two zinc layers. The resulting intermediate layer shields the two base materials from each other. As a result, both the formation of brittle intermediate compounds and the contact corrosion are avoided. This is due to the fact of the lower melting point of the zinc, which was mentioned in the beginning. The melting of the base materials and their mixing can also be excluded on the base of the shown cross section.

The results of the EDX analysis in connection with the not reached melting point of the zinc layer on the solid parts imply a diffusion bonding joining process. To verify this thesis, further researches have to be carried out.

After the metallographic characterization of the joining zone, the head and shear tensile strengths of the compound were determined as a function of the process input variables.

The maximum strength values were achieved with the joining parameters in Table 4. For measuring the force and strength values, the experimental setup in Fig. 10 was used. In the shear tensile test, the force was applied horizontally to

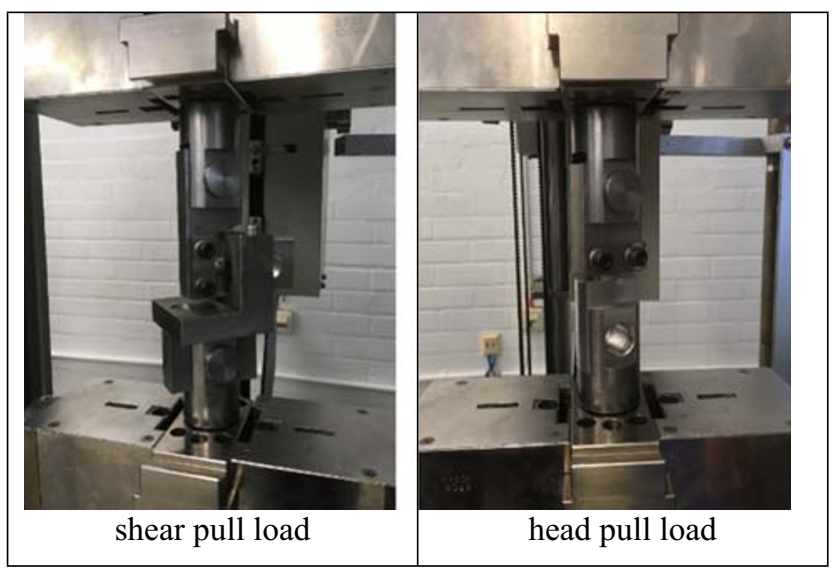

Fig. 10 Experimental setup for tensile testing

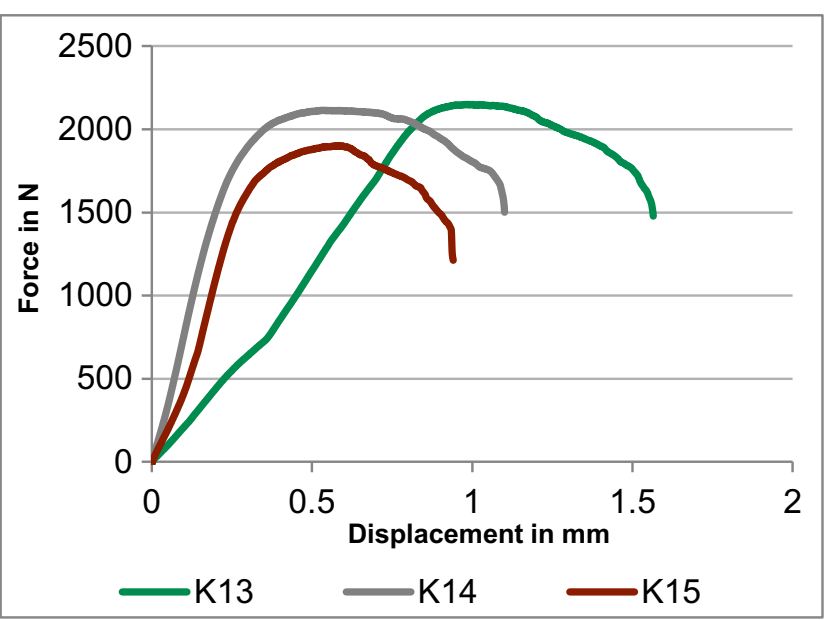

Fig. 11 Force-displacement diagram for tensile strength

the joining plane, while in the head tensile test, the force was applied vertically.

The force-displacement curves of the three repeating tests to confirm the results are shown in Fig. 11 (head tensile strength) and Fig. 12 (shear tensile strength).

The samples, which were joined at an oven temperature of $455^{\circ} \mathrm{C}$, a force of $27.5 \mathrm{kN}$, and a punch speed of $11.5 \mathrm{~mm} / \mathrm{min}$ thus endure the highest forces. The average values under load are $2.1 \mathrm{kN}$ and under load stress $11.4 \mathrm{kN}$.

Figure 13 shows specified strength values for the hybrid forging specimens and in comparison for resistance spot welding and clinching processes. The values for the resistance spot welding and the clinching process were measured specimens, which were made of AlMg4.5Mn sheet metal with a thickness of $1 \mathrm{~mm}$ and the steel sheet metal from the hybrid forging process specimens. For all values, the measured force was related to the load bearing cross section. The hybrid forging process provides higher strength as the conventional processes.

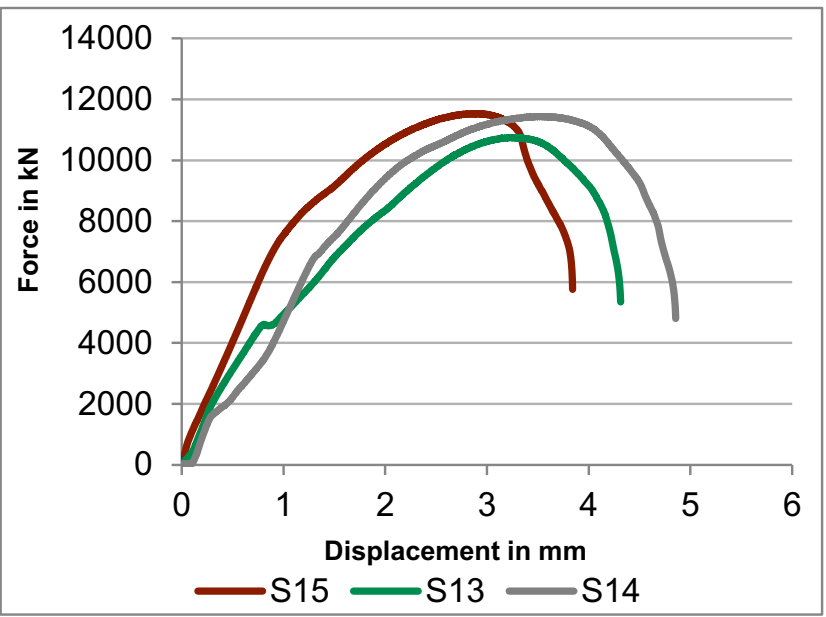

Fig. 12 Force-displacement diagram for shear strength 


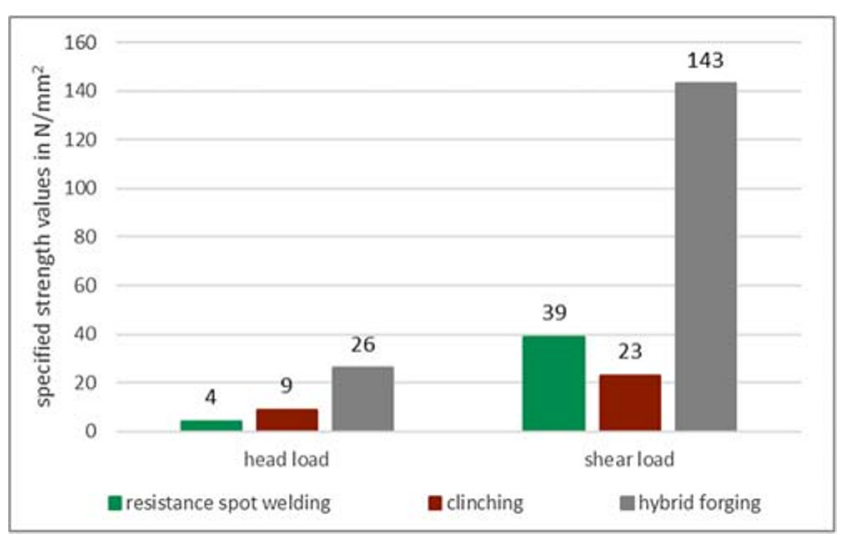

Fig. 13 Specified strength values in comparing with resistance spot welding and clinching process

After the experiments, the fracture surfaces were subjected to EDX analysis. In this case, the distribution of the elements over the connection surface was determined to analyze the material transfer and thus to prove the cohesive connection. Figure 14 a shows the fracture surface on the steel side. The distribution of the elements iron, zinc, and aluminum for this range are shown in Fig. 14b-d. The edge area clearly shows a gap in the zinc layer. This indicates a cohesive connection of the two zinc layers, so that it comes to the replacement of the zinc layer on the steel at the break. However, it also shows that no full-surface connection was achieved during joining.

\section{Conclusion}

The presented studies lead to two significant results.

On the one hand, the process parameters for hot-dip galvanizing of aluminum were identified. By wet-chemical adjustment of the composition, the quality of the coating could be significantly improved. The expression of the layer on the surface is controlled by diffusion, so that a dependence on the immersion time and the melt bath temperature results. However, further investigations must be carried out to adjust the layer thickness and its influence on the strength of the joint.

On the other hand, the process parameters to produce an integral connection between the galvanized aluminum alloy solid part and the galvanized steel sheet were investigated by composite forging. Based of statistical experimental design, a process window could be determined, which leads to comparatively high strengths of the connection under head and shear load $(2.1 \mathrm{kN}$ or $11.4 \mathrm{kN})$. The cohesive connection could be detected by SEM analyses and metallographic sections. However, the process was unable to create full-surface connections. Therefore, further investigations are necessary, with the goal of achieving a full-surface connection. However, the base materials were hardly influenced by diffusion during the joining process. However, due to the large compression of the

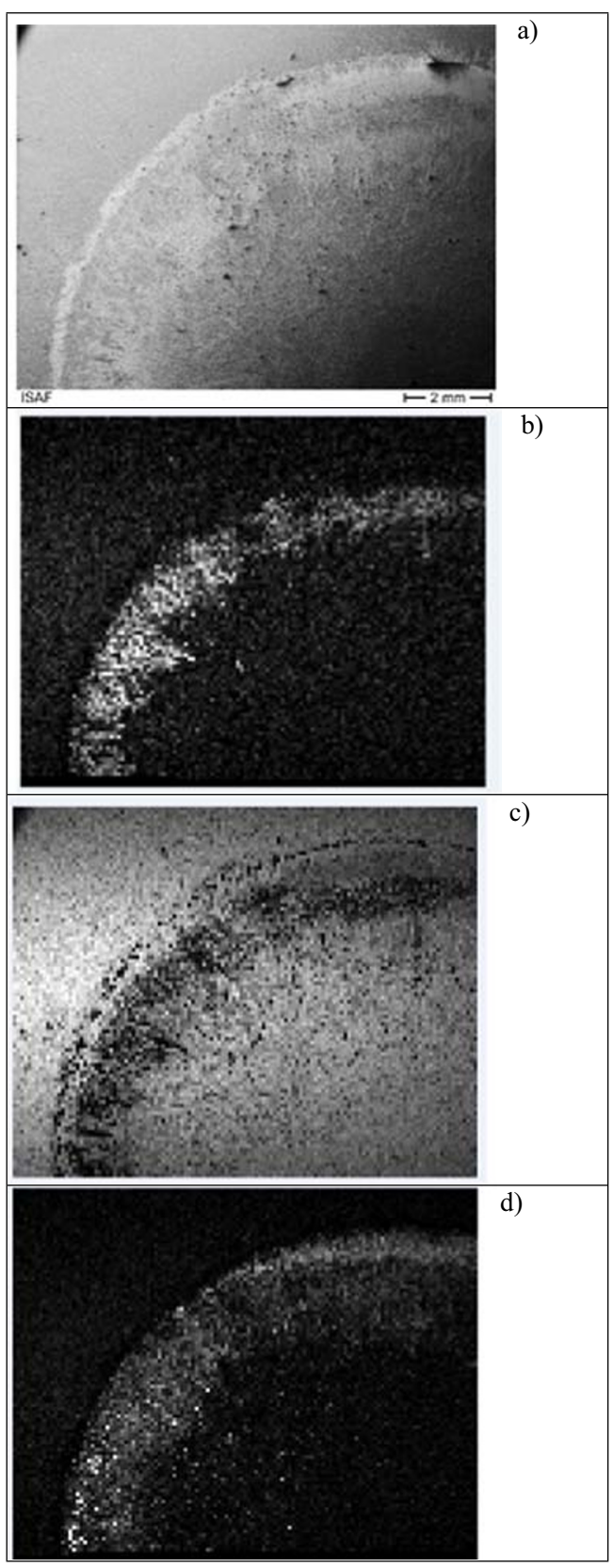

Fig. 14 SEM picture of the fracture surface (a), element distribution of Fe (b), $\mathrm{Zn}(\mathbf{c})$ and $\mathrm{Al}(\mathbf{d})$

materials with residual stresses, which must also be determined.

The comparison of the determined strength values with the values of joint connections of similar punctiform geometries shows the high potential of the method. The strengths of joints made by conventional joining techniques, such as resistance spot welding, clinching, or riveting, have been achieved or even surpassed in hybrid composite forging.

Further investigations into the relationship between joining energy and strength as well as the influence of the composition of different zinc layers are intended to expand the process understanding. Through simulation and validation 
experiments, the modeling process will be transferred to industrial forging technology.

Acknowledgments Open Access funding enabled and organized by Projekt DEAL. Special thanks go to the German Research Foundation, which has made this work possible through financial support.

Open Access This article is licensed under a Creative Commons Attribution 4.0 International License, which permits use, sharing, adaptation, distribution and reproduction in any medium or format, as long as you give appropriate credit to the original author(s) and the source, provide a link to the Creative Commons licence, and indicate if changes were made. The images or other third party material in this article are included in the article's Creative Commons licence, unless indicated otherwise in a credit line to the material. If material is not included in the article's Creative Commons licence and your intended use is not permitted by statutory regulation or exceeds the permitted use, you will need to obtain permission directly from the copyright holder. To view a copy of this licence, visit http://creativecommons.org/licenses/by/4.0/.

\section{References}

1. Su Y, Hua X, Wu Y (2014) Influence of alloy elements on microstructure and mechanical property of aluminum-steel lap joint made by gas metal arc welding. J Mater Process Technol 214(4):750-755

2. Nguyen VN, Nguyen QM, Huang S-C (2018) Microstructure and mechanical properties of butt joints between stainless steel SUS304L and aluminum alloy A6061-T6 by TIG welding. Materials 11:1136

3. Meco S, Pardal G, Ganguly S, Miranda RM, Quintino L, Williams S (2013) Overlap conduction laser welding of aluminium to steel. Int J Adv Manuf Technol 67(1-4):647-654

4. Meco S, Cozzolino L, Ganguly S, Williams S, McPherson N (2017) Laser welding of steel to aluminium: thermal modelling and joint strength analysis. J Mater Process Technol 247:121-133

5. Meco S, Ganguly S, Williams S, McPherson N (2014) Effect of laser processing parameters on the formation of intermetallic compounds in Fe-Al dissimilar welding. J Mater Eng Perform 23(9): 3361-3370

6. Kashani HT, Kah P, Martikainen J (2015) Laser overlap welding of zinc-coated steel on aluminum alloy. Phys Procedia 78:265-271

7. Zhang G, Su W, Zhang J, Wei Z (2011) Friction stir brazing: a novel process for fabricating $\mathrm{Al} /$ steel layered composite and for dissimilar joining of Al to steel. Metall Mater Trans A 42(9): 2850-2861

8. Dong H, Hu W, Duan Y, Wang X, Dong C (2012) Dissimilar metal joining of aluminum alloy to galvanized steel with $\mathrm{Al}-\mathrm{Si}, \mathrm{Al}-\mathrm{Cu}$, $\mathrm{Al}-\mathrm{Si}-\mathrm{Cu}$ and $\mathrm{Zn}-\mathrm{Al}$ filler wires. J Mater Process Technol 212(2): 458-464
9. Dharmendra C, Rao KP, Wilden J, Reich S (2011) Study on laser welding-brazing of zinc coated steel to aluminum alloy with a zinc based filler. Mater Sci Eng A 528(3):1497-1503

10. Chen J, Yuan X, Hu Z, Li T, Wu K, Li C (2017) Improvement of resistance-spot-welded joints for DP 600 steel and A5052 aluminum alloy with Zn slice interlayer. J Manuf Process 30:396-405

11. Chen N, Wang M, Wang H-P, Wan Z, Carlson BE (2018) Microstructural and mechanical evolution of $\mathrm{Al} /$ steel interface with $\mathrm{Fe} 2 \mathrm{Al} 5$ growth in resistance spot welding of aluminum to steel. $\mathrm{J}$ Manuf Process 34:424-434

12. Chen S, Huang J, Ma K, Zhang H, Zhao X (2012) Influence of a Nifoil interlayer on $\mathrm{Fe} / \mathrm{Al}$ dissimilar joint by laser penetration welding. Mater Lett 79:296-299

13. Kimapong K, Watanabe T (2005) Lap joint of A5083 aluminum alloy and SS400 steel by friction stir welding. Mater Trans 46(4): 835-841

14. Helal Y, Boumerzoug Z, Fellah L (2019) Microstructural evolution and mechanical properties of dissimilar friction stir lap welding aluminum alloy 6061-T6 to ultra low carbon steel. Energy Procedia 157:208-215

15. Das H, Ghosh RN, Pal TK (2014) Study on the formation and characterization of the intermetallics in friction stir welding of aluminum alloy to coated steel sheet lap joint. Metall Mater Trans A 45(11):5098-5106

16. Zhou L, Yu M, Liu B, Zhang Z, Liu S, Song X, Zhao H (2020) Microstructure and mechanical properties of $\mathrm{Al} /$ steel dissimilar welds fabricated by friction surfacing assisted friction stir lap welding. J Mater Res Technol 9(1):212-221

17. Bick T, Heuler V, Treutler K et al (2020) Characterization of influences of steel-aluminum dissimilar joints with intermediate zinc layer. Metals 10(4):442

18. Bick T, Treutler K, Wesling V (2019) "Charakterisierung der Verbindungseigenschaften hybrid verbundgeschmiedeter Stahl Aluminium Mischverbindungen in Abhängigkeit der Zinkschichtzusammensetzung," in 39. Assistentenseminar Fügeund Schweißtechnik: Vorträge der gleichnamigen Veranstaltung in Eupen vom 12. bis 14. September 2018, pp. 113-120

19. Behrens B-A, Kosch K-G (2011) Influence of different alloying elements on the intermetallic phase seam thickness of compound forged steel-aluminum parts. Prod Eng 5(5):517-522

20. Behrens B-A, Kosch K-G (2011) Development of the heating and forming strategy in compound forging of hybrid steel-aluminum parts. Mater Werkst 42(11):973-978

21. Behrens B-A, Holz F (2008) Verbundschmieden hybrider StahlAluminium Bauteile. Mater Werkst 39(9):599-603

22. Perrot $\mathrm{P}$, Tedenac J. Al-Zn binary phase diagram evaluation. MSI, Materials Science International, Stuttgart. http://www.msi-eureka. com/full-html/20.10926.1.8/Al-Zn Binary Phase Diagram Evaluation/. Accessed 25 March 2020

Publisher's note Springer Nature remains neutral with regard to jurisdictional claims in published maps and institutional affiliations. 